\title{
On Benzofuroindole Analogues as Smooth Muscle Relaxants
}

\author{
Ike dela Peña and Jae Hoon Cheong \\ Uimyung Research Institute for Neuroscience and Department of Pharmacology, Sahmyook University, 26-21 Kongkreung-dong, \\ Nowon-gu, 139-742 Seoul, Republic of Korea
}

Correspondence should be addressed to Jae Hoon Cheong, cheongjh@syu.ac.kr

Received 3 May 2011; Accepted 14 July 2011

Academic Editor: J.-P. Jin

Copyright ( 2011 I. dela Peña and J. H. Cheong. This is an open access article distributed under the Creative Commons Attribution License, which permits unrestricted use, distribution, and reproduction in any medium, provided the original work is properly cited.

\begin{abstract}
At least two laboratories have independently reported the synthesis of benzofuroindole compounds having potential therapeutic implications in many disease states including those that involve smooth muscle hyperactivity. Through a series of in vitro screenings, they demonstrated the efficacy (and selectivity) of these compounds to potentiate large conductance calcium$\left(\mathrm{Ca}^{2+}-\right)$ activated $\mathrm{K}^{+}\left(\mathrm{BK}_{\mathrm{Ca}}\right)$ channels, by far, the most characterized of all $\mathrm{Ca}^{2+}$-dependent $\mathrm{K}^{+}$channels. Interestingly, promising benzofuroindole derivatives such as compound 7 (10H-benzo[4,5]furo[3,2-b]indole) and compound 22 (4-chloro7-trifluoromethyl-10H-benzo[4,5] furo[3,2-b]indole-1-carboxylic acid) both exhibited high bladder (versus aorta) selectivity, making them attractive alternative treatments for bladder overactivity. In recent reports, compound 22 (LDD175 or TBIC) also showed inhibition of ileum and uterine contractions, indicating multiple target tissues, which is not surprising as $\mathrm{BK}_{\mathrm{Ca}}$ channels are ubiquitously expressed in the animal and human tissues. In this paper, the authors discuss the value of benzofuroindole compounds and the challenges that need to be overcome if they were considered as smooth muscle relaxants.
\end{abstract}

\section{Introduction}

Smooth muscle contraction plays a fundamental role in regulating the functions of the hollow organs in the body such as the blood vessels, intestines, bladder, airways, and uterus. Dysfunctional contraction of the smooth muscles is a key pathological feature of many diseases including hypertension, bladder overactivity $(\mathrm{OAB})$, irritable bowel syndrome, erectile dysfunction, and asthma. Abnormal uterine contractions may also lead to preterm labor, the latter being responsible for prenatal mortality, neonatal morbidity, and childhood developmental disorders [1]. By and large, smooth muscle hyperactivity disorders involve immense social cost and financial burden to the health services, thus, a considerable effort has been made to understand their etiologies and also to develop drugs with potent smooth muscle relaxant activities.

Contractions of all smooth muscles absolutely depend on the presence of $\mathrm{Ca}^{2+}$ which activates the contractile machineries [2,3]. Elevating intracellular $\mathrm{Ca}^{2+}$, which can be achieved by agonists (e.g., acetylcholine, oxytocin, and prostaglandin F2 $\alpha$ ), causes smooth muscle contractions. Acetylcholine $(\mathrm{ACh})$, the main contractile transmitter in many smooth muscle tissues (e.g., the urinary bladder and gastrointestinal tract), activates muscarinic $\left(\mathrm{M}_{3}\right)$ receptors and raises intracellular $\mathrm{Ca}^{2+}$ levels by activating the Gq-phospholipase C- (PLC-) inositol triphosphate $\left(\mathrm{IP}_{3}\right)$ pathway [4]. It is also believed that extracellular $\mathrm{Ca}^{2+}$ facilitates an increase in intracellular $\mathrm{Ca}^{2+}$ via opening of the voltage-gated $\mathrm{Ca}^{2+}$ channels [5]. $\mathrm{M}_{2}$ receptor binding of ACh also elevates intracellular $\mathrm{Ca}^{2+}$ through a number of controversial mechanisms including inhibition of the production of cyclic AMP (cAMP) [6]. In the bladder smooth muscles, where muscarinic receptor is the primary efferent receptor, agonist-induced contraction is largely dependent on $\mathrm{Ca}^{2+}$ entry through nifedipine-sensitive channels and activation of the Rho-kinase pathway [7]. On the other hand, oxytocin and prostaglandin F $2 \alpha$ act on oxytocin and prostaglandin receptors, respectively, and release $\mathrm{Ca}^{2+}$ from intracellular stores through stimulation of the Gq-PLC-IP 3 system [8-10]. They may also propagate the influx of extracellular $\mathrm{Ca}^{2+}$ through voltage-gated L-channels [11]. In addition, oxytocin may activate nonselective cation channels and $\mathrm{Ca}^{2+}$-activated $\mathrm{Cl}^{-}$channels leading to depolarization of myometrial cells and, eventually, the opening of voltage-dependent $\mathrm{Ca}^{2+}$ channels $[2,11]$. In light of these 
observations, drugs that could block the effects of these agonists induce smooth muscle relaxation through some mechanisms that could block or interfere with $\mathrm{Ca}^{2+}$ entry. Antimuscarinic agents, those that oppose the effects of ACh, are effective bladder and intestinal smooth muscle relaxants and are well-known standard therapies for $\mathrm{OAB}$ and in some forms of gastrointestinal motility disorders. In addition, $\mathrm{Ca}^{2+}$ channel blockers (CCBs) are effective OAB interventions although they are more commonly used for hypertension and other cardiovascular diseases. CCBs block $\mathrm{Ca}^{2+}$ entry by binding to the L-type $\mathrm{Ca}^{2+}$ channels in the heart and smooth muscles of the peripheral vasculature, thereby generating vasodilation and eventually lowering blood pressure [12]. Oxytocin antagonists, CCBs, prostaglandin synthase inhibitors, and $\beta$-adrenergic agonists are used as tocolytics (medications to suppress premature labor) by virtue of their influence on lowering intracellular $\mathrm{Ca}^{2+}$ levels. $\beta$-adrenergic agonists, alike some nonsteroidal anti-inflammatory drugs, increase the level of cAMP which results in the decrease in intracellular $\mathrm{Ca}^{2+}$ by stimulating efflux of $\mathrm{Ca}^{2+}$ from the cell and also uptake by the sarcoplasmic reticulum [13].

However impressive the above-named agents are in managing abnormal smooth muscle contractions, their efficacy and application are limited due to some reported druginduced side effects. In fact, the application of these compounds may exacerbate the diseases albeit only in extreme cases [14]. Antimuscarinic drugs, although effective in inhibiting bladder and intestinal contractility, also influence normal contractility thus affecting normal voiding and excretion functions. Moreover, muscarinic $\mathrm{M}_{3}$ receptors are found in the salivary glands thus severe dry mouth is expected with the use of antimuscarinic agents [14]. The standard tocolytics, although efficacious in arresting preterm labor, also produce serious maternal and cardiovascular or adverse fetal side effects $[15,16]$. Altogether, these findings indicate that there is a necessity to develop other smooth muscle relaxants, preferably those that act on a different mechanism.

Another way to counteract defective smooth muscle contractility is to enhance repolarizing (potassium $\left[\mathrm{K}^{+}\right]$) currents [17]. $\mathrm{K}^{+}$channels are abundantly expressed in smooth muscles where they play an important role in determining and regulating the excitability of the cell by acting as an excitability "brake." A number of $\mathrm{K}^{+}$channel openers have been developed, and they showed promise in preclinical and clinical studies for a variety of smooth muscle hyperactivity disorders. Among them are the openers of the ATP sensitive $\mathrm{K}^{+}\left(\mathrm{K}_{\mathrm{ATP}}\right)$ channels and $\mathrm{Ca}^{2+}$-activated $\mathrm{K}^{+}\left(\mathrm{K}_{\mathrm{Ca}}\right)$ channels. However, as $\mathrm{K}^{+}$channels are ubiquitously expressed in virtually all cell types, it has been thought that $\mathrm{K}^{+}$channel openers may not show tissue selectivity. Indeed, the most investigated $\mathrm{K}_{\text {ATP }}$ channel openers pinacidil and cromakalim effectively abolished unwanted bladder contractions without affecting normal voiding [18]. However, they also exhibited limited bladder selectivity and influenced cardiovascular functions [19-23].

At least two noncollaborating laboratories have reported the synthesis of novel $\mathrm{K}^{+}$channel openers which they thought as effective interventions for smooth muscle hyperactivity disorders, particularly in OAB. Butera and colleagues
[24] first reported the production of benzofuroindole analogues in their continued effort to develop potent bladder relaxants with minimal hemodynamic effects. These benzofuroindole compounds were produced by manipulating the structure of the benzopyran-based antihypertensive and prototype $\mathrm{K}_{\mathrm{ATP}}$ channel opener celikalim. Initial structural modifications of celikalim accidentally led to the production of the Fisher-indole product $10 \mathrm{H}$-benzo[4,5] furo[3,2-b] indole (compound 7) (Figure 1), a derivative which displayed not only potent bladder relaxant effects in in vitro screenings, but also high bladder (versus aorta) selectivity. On the other hand, another group produced benzofuroindole compounds by overlaying compound 7 (see above), with BMS-204352, a prototypical opener of one type of $\mathrm{K}_{\mathrm{Ca}}$ channels, the large conductance $\mathrm{Ca}^{2+}$-activated $\mathrm{K}^{+}\left(\mathrm{BK}_{\mathrm{Ca}}\right)$ channel [25]. One of the derivatives, compound 22, (4-chloro-7-trifluoromethyl-10H-benzo[4,5] furo[3,2-b]indole-1-carboxylic acid) (Figure 1) demonstrated in vitro inhibition of bladder contractions without influencing contractility of the blood vessels [26]. Multiple analyses showed that the abovementioned benzofuroindole compounds were potent activators of the $\mathrm{BK}_{\mathrm{Ca}}$ channels [24-26]. $\mathrm{BK}_{\mathrm{Ca}}$ channels, relative to other $\mathrm{K}^{+}$channel types, have more superior biophysical, molecular, and pharmacological properties making them more appealing targets to achieve smooth muscle relaxation (see below). In the succeeding sections, the attractive features of benzofuroindole compounds as smooth muscle relaxants are described, as well as some of the concerns that need to be addressed if they were used clinically as antispasmodics or tocolytics.

\section{Benzofuroindole Compounds, $\mathrm{BK}_{\mathrm{Ca}}$ Channels, and Their Activators}

As stated above, the first ever synthesized benzofuroindole analogue (compound 7) was derived from a $\mathrm{K}_{\text {ATP }}$ channel opener. Thus, it came as a surprise when the compound potently activated the $\mathrm{BK}_{\mathrm{Ca}}$ channels. Accordingly, the effects of compound 7 were readily reversed by the specific $\mathrm{BK}_{\mathrm{Ca}}$ channel blocker iberiotoxin, but not by glyburide (a selective $\mathrm{K}_{\text {ATP }}$ channel blocker). Furthermore, voltage clamp studies on isolated rat bladder myocytes showed that the compound caused an iberiotoxin-sensitive increase in hyperpolarizing current, further intensifying its $\mathrm{BK}_{\mathrm{Ca}}$ channel-potentiating properties [24]. On the other hand, Gormemis et al. [25] reported another set of benzofuroindole compounds that are also potent $\mathrm{BK}_{\mathrm{Ca}}$ channel openers. Compound 22, along with other novel benzofuroindole derivatives, was shown to effectively potentiate cloned $\mathrm{BK}_{\mathrm{Ca}}$ channels expressed in Xenopus laevis oocytes. The ionic currents caused by compound 22 were blocked by the peptide $\mathrm{BK}_{\mathrm{Ca}}$ channel blocker charybdotoxin indicating selective activation of the $\mathrm{BK}_{\mathrm{Ca}}$ channels [25]. Further electrophysiological characterizations of one the potent derivatives, compound 8 (7-trifluoromethyl- $10 \mathrm{H}$ benzo[4,5]furo[3,2- $b]$ indole-1-carboxylic acid), showed that it highly activated cloned $\mathrm{BK}_{\mathrm{Ca}}$ channels from the extracellular side independent of $\beta$ subunits and regardless of the presence of intracellular $\mathrm{Ca}^{2+}$ (for a review on $\mathrm{BK}_{\mathrm{Ca}}$ channel structure, see Figure 2 ). In addition, it activated native $\mathrm{BK}_{\mathrm{Ca}}$ 


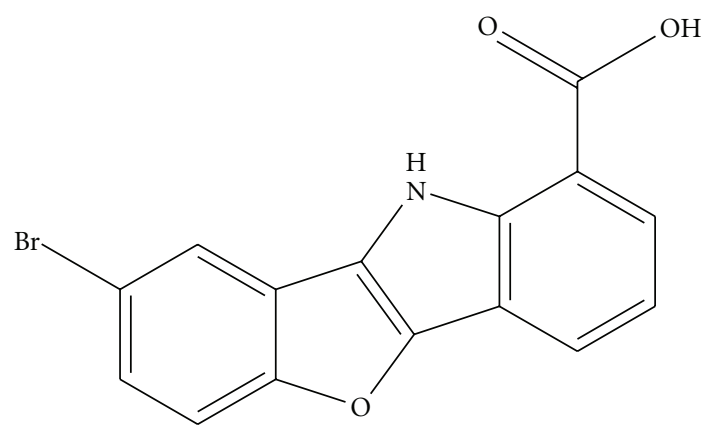

Compound 7

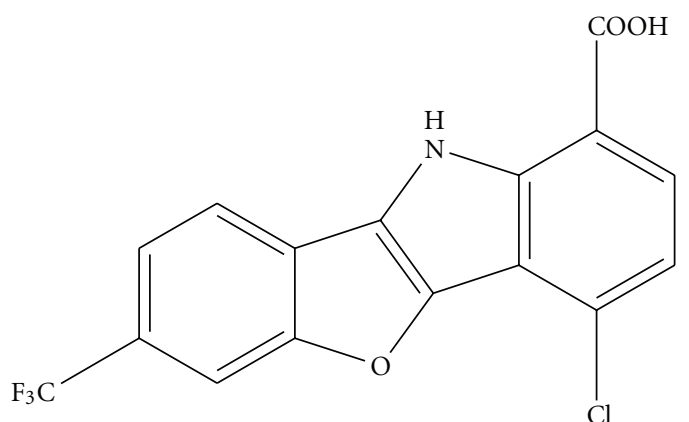

Compound 22

Figure 1: Structures of compound 7 (10H-benzo[4,5]furo[3,2- $b$ ]indole) and compound 22 (4-chloro-7-trifluoromethyl-10Hbenzo[4,5] furo[3,2-b]indole-1-carboxylic acid).

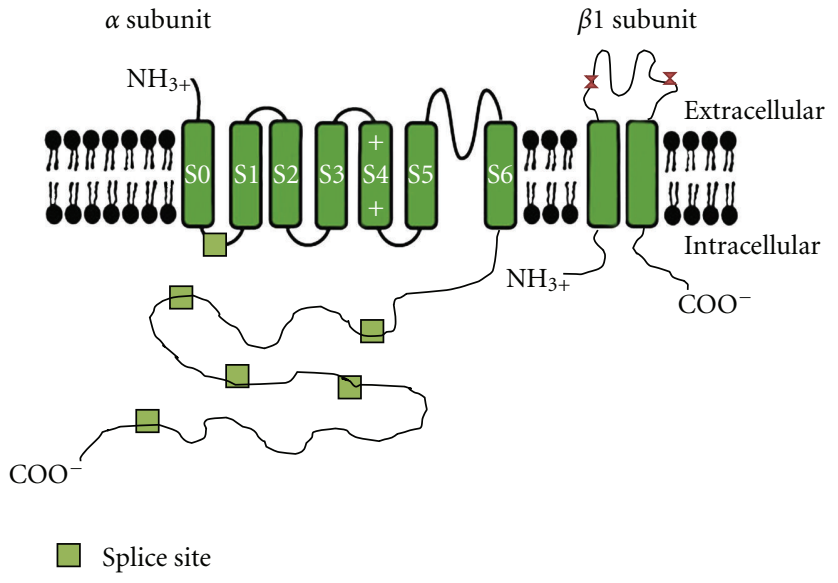

(a)

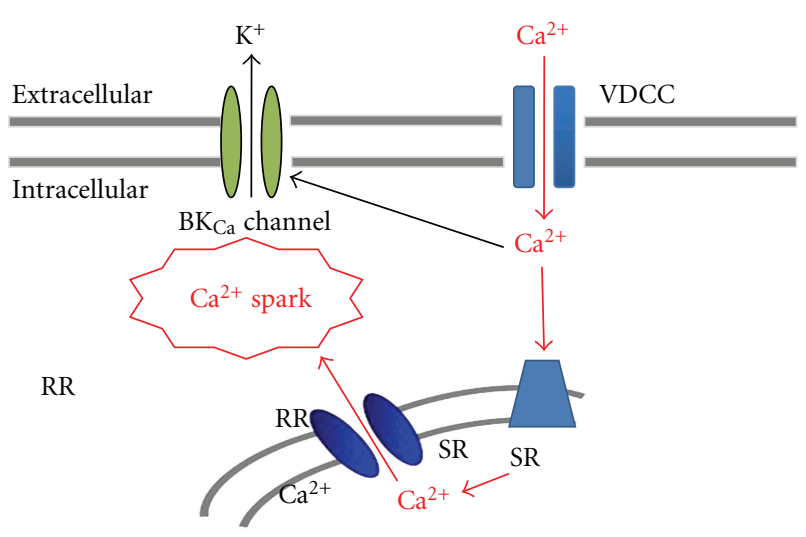

(b)

FIGURE 2: Structure and physiology of $\mathrm{BK}_{\mathrm{Ca}}$ channels. (a) BK $\mathrm{Ca}_{\mathrm{C}}$ channels are composed of two different subunits: the pore-forming $\alpha$ subunit and the auxiliary $\beta$ subunits. A functional channel is made up by the association of four $\alpha$ and four $\beta 1$ subunits. Although a single gene codes for $\alpha$, splicing leads to variants that are different in biophysical properties and/or intracellular localization. (b) In smooth muscles, membrane depolarization and/or intracellular $\mathrm{Ca}^{2+}$ cause the influx of $\mathrm{Ca}^{2+}$ through voltage-dependent Ca ${ }^{2+}$ channels (VDCCs). This in turn causes a rise in intracellular $\mathrm{Ca}^{2+}$ levels and smooth muscle contraction. Increases in $\mathrm{Ca}^{2+}$ levels facilitate $\mathrm{Ca}^{2+}$ binding to ryanodine receptors (RRs) in the sarcoplasmic reticulum (SR), which produces a localized $\mathrm{Ca}^{2+}$ release $\left(\mathrm{Ca}^{2+}\right.$ spark) that activates the $\mathrm{BK}$ Ca channels. Activation of $\mathrm{BK}_{\mathrm{Ca}}$ channels causes efflux of $\mathrm{K}^{+}$, hyperpolarization of the cell membrane, closure of VDCC, prevention of $\mathrm{Ca}^{2+}$ entry, and eventually smooth muscle relaxation. Adapted from Garcia et al. [27].

channels from rat hippocampus pyramidal neurons [28], a finding which might have important clinical roles. But just how remarkable is it when a compound is an opener of the $\mathrm{BK}_{\mathrm{Ca}}$ channels?

Some excellent reviews on the structure, pharmacology, functions (Figure 2), and the potentiality of $\mathrm{BK}_{\mathrm{Ca}}$ channels as novel therapeutic targets have been made [29, 30]. Structurally, $\mathrm{BK}_{\mathrm{Ca}}$ channels are composed of two different subunits: the pore-forming $\alpha$ subunit and the auxiliary $\beta$ subunits. Although channels formed only by four $\alpha$ subunits can be functional, $\beta$ subunits alter the biophysical and pharmacological properties of homomeric channels, including $\mathrm{Ca}^{2+}$ and voltage sensitivity and gating kinetics [28, 31-34]. These characteristics of $\mathrm{BK}_{\mathrm{Ca}}$ channels make them appealing targets, and their activators potent therapies for many diseases: (1) abundant distribution like other $\mathrm{K}^{+}$ channel types, (2) high conductance ( $200 \mathrm{pS})$ even at low probability of opening, thus facilitating more efficient $\mathrm{K}^{+}$ efflux and membrane hyperpolarization (relaxation), (3) high sensitivity to both intracellular $\mathrm{Ca}^{2+}$ concentrations and voltage, (4) $\mathrm{Ca}^{2+}$ independence, that is, $\mathrm{BK}_{\mathrm{Ca}}$ channels can open even in the absence of $\mathrm{Ca}^{2+}$ and the $\mathrm{Ca}^{2+}$ and membrane potential dependence of the channels are independent of each other $[29,30]$.

A number of $\mathrm{BK}_{\mathrm{Ca}}$ channel openers, derived from natural products and from synthetic chemistry, have been developed and reported (e.g., dehydrosoyasaponin-I, maxikdiol, NS1619, BMS-204352, 17 $\beta$-estradiol, ethylbromidetamoxifen, pimaric acid, and epoxyeicosatrienoic acids [3538]. These substances, however, differ in properties and 

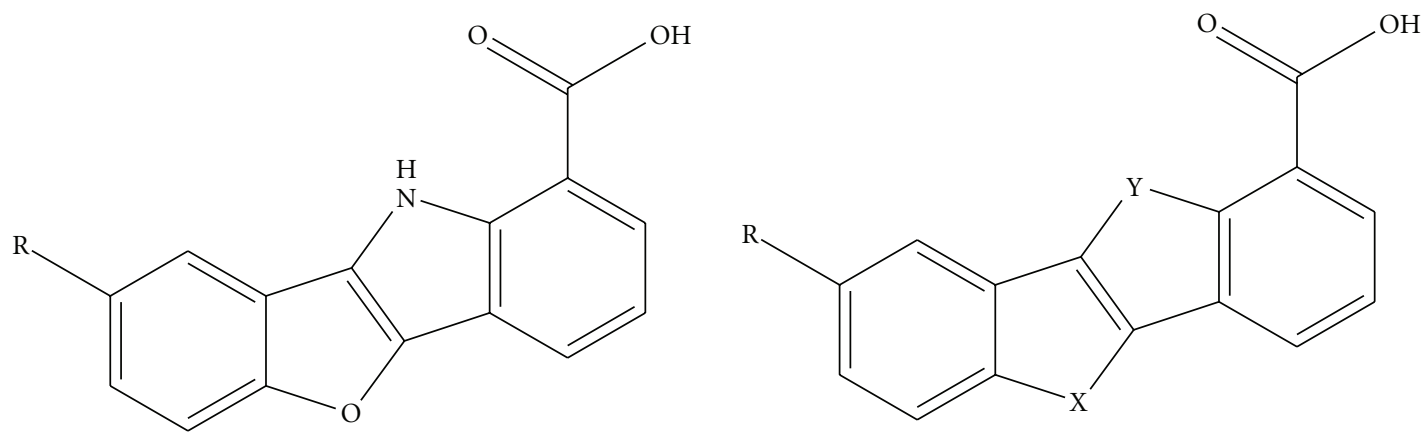

$$
\begin{aligned}
7 \mathrm{R} & =\mathrm{Br} \\
14 \mathrm{R} & =\mathrm{I} \\
15 \mathrm{R} & =\mathrm{Cl}
\end{aligned}
$$

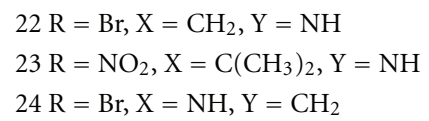

FIGURE 3: Structures of the highly bladder (versus aorta) selective benzofuroindole compounds synthesized by Butera et al. [24].

in some respects, mechanisms of action. For instance, dehydrosoyasaponin-I and $17 \beta$-estradiol may require $\beta$ subunits for optimum channel potentiation $[31,39]$, while some compounds (e.g., dehydrosoyasaponin-I and $17 \beta$-estradiol) may act only on the intracellular side of the channel by being highly impermeable [40]. Unexpectedly, given the potentiality of $\mathrm{BK}_{\mathrm{Ca}}$ channel openers as future interventions in many disease states, it is surprising that only four $\mathrm{BK}_{\mathrm{Ca}}$ channel openers have entered clinical development (NS-8, TA-1702, BMS-223131, and BMS-204352) [27]. To the best of our knowledge, clinical trials for the $\mathrm{BK}_{\mathrm{Ca}}$ channel openers NS8, BMS204352, and TA-1702 have been discontinued, while only one drug candidate, andolast (for the treatment of asthma), remains in the early phase of clinical development [41]. In the view of Garcia et al. [27], there is still much validation required for $\mathrm{BK}_{\mathrm{Ca}}$ channel openers to progress as future smooth muscle relaxants. Novel $\mathrm{BK}_{\mathrm{Ca}}$ channel openers must show appropriate potency and selectivity, efficacy in preclinical disease models, and, most of all, lesser toxicity [27].

\section{Benzofuroindole Compounds, $\mathrm{BK}_{\mathrm{Ca}}$ Channel Openers with Bladder (versus Aorta) Selectivity}

Aside from remarkably potentiating $\mathrm{BK}_{\mathrm{Ca}}$ channels from rat bladder myocytes, benzofuroindole compounds developed by Butera and colleagues were also shown to be highly bladder selective with aorta/bladder $\mathrm{IC}_{50}$ ratios ranging from 8 - to 46-fold. This was ascertained through organ bath studies with isolated rat bladder and aortic rings. In their studies, compound 15 showed to be the most bladder selective $\left(\mathrm{IC}_{50}\right.$ ratio aorta/bladder $\left.=46\right)$. The structure-activity relationships for these compounds have been reported and reviewed [14, 24]. By looking at the structures of compounds 7, 14, 15 and those of the other highly bladder selective derivatives (compounds 22, 23, and 24), bladder specificity could be attributed to the imbedded 5,5 ring system that is fairly tolerant of structural modifications [14] (Figure 3). Meanwhile, dela Peña et al. [26] also disclosed the bladder (versus aorta) selectivity profile of compound 22, the benzofuroindole analogue synthesized by Gormemis and colleagues. In their multiple screenings, compound 22 or LDD 175 displayed 20 -fold selectivity for the rat bladder compared with the aorta (when $E_{\max }$ values are compared) [26]. What is more, compound 22 did not have any significant vasorelaxant activity. In vivo screenings in the Spontaneously Hypertensive rat (SHR), an animal model of hypertension also showed that compound 22 did not alter the rat's hemodynamic activities. In addition, the same group demonstrated that oral administration of compound 22 reduced voiding frequency and lengthened void intervals in SHR, a putative animal model of OAB [42]. It is noteworthy that these effects were seen only in the SHR and not in the normotensive strain, the Wistar Kyoto rats, a finding that might have significant clinical implications.

In certain disease states such as $\mathrm{OAB}$, a major drawback of current pharmacotherapies as well as those drugs in development, is their ability to affect cardiovascular activities. $\mathrm{K}_{A T P}$ channel openers, compounds first developed for $\mathrm{OAB}$, also activated $\mathrm{K}_{\mathrm{ATP}}$ channels in the heart and peripheral blood vessels and brought hemodynamic side effects. For this reason, the development of $\mathrm{K}_{\mathrm{ATP}}$ drugs for OAB has been abandoned in recent years [14]. The focus has been shifted to other $\mathrm{K}^{+}$channel openers, such as $\mathrm{BK}_{\mathrm{Ca}}$ and the recently identified KCNQ channels openers [14]. Compared with $\mathrm{K}_{\mathrm{ATP}}$ channels, $\mathrm{BK}_{\mathrm{Ca}}$ channels are less expressed in the heart tissue $[29,30]$ but are abundant in the bladder smooth muscles and also in neuronal tissues. With regard to their expression in neuronal tissues, $\mathrm{BK}_{\mathrm{Ca}}$ activators could then impact $\mathrm{OAB}$ whether the underlying etiology is either neurogenic or myogenic in nature [14]. In fact, it is proposed that targeting the neuronal channels could minimize cardiovascular side effects, although it might also lead to the emergence of unwanted neuronal side effects [14]. 
TABLE 1: $\mathrm{EC}_{50}$ values (concentration producing $50 \%$ of maximum inhibition of spontaneous or agonist-induced contractions) of compound 22 in the isolated bladder, ileum and uterus.

\begin{tabular}{lccc}
\hline \multicolumn{4}{c}{ EC $_{50}$ values $(\mu \mathrm{M})$} \\
$\begin{array}{l}\text { Effects of compound 22 } \\
\text { in }\end{array}$ & $\begin{array}{c}\text { Bladder } \\
{[26]}\end{array}$ & $\begin{array}{c}\text { Ileum } \\
{[43]}\end{array}$ & $\begin{array}{c}\text { Uterus } \\
{[44]}\end{array}$ \\
\hline $\begin{array}{l}\text { Spontaneous } \\
\text { contractions }\end{array}$ & n.e. & 1.25 & 4.63 \\
\hline $\begin{array}{l}\text { Agonist-induced } \\
\text { contractions }\end{array}$ & & & \\
\hline \multicolumn{1}{c}{ ACh $(1 \mu \mathrm{M})$} & 1.25 & 5.01 & 4.37 \\
$\quad$ EFS & n.e. & 3.16 & n.t. \\
$\quad$ High $\mathrm{k}^{+}(20 \mathrm{mM} \mathrm{KCI})$ & 2.51 & 0.79 & 3.04 \\
\hline
\end{tabular}

n.e.: no effect, n.t.: not tested.

\section{Compound 22 and Its Effects in Other Smooth Muscles}

$\mathrm{BK}_{\mathrm{Ca}}$ channels are abundantly distributed in many smooth muscle types such as gastrointestinal smooth muscles [41] and the uterus [45-47]. As not much is known about the effects of benzofuroindole compounds in other tissues, an ongoing effort has been made to investigate this matter. Compound 22 also displayed potent inhibition of both spontaneous and agonist-induced contractions of the ileum [43] and uterus [44]. EC 50 values of the relaxant effects of compound 22 are shown in Table 1. While compound 22 did not have any intrinsic relaxant activity in the bladder (suggesting its lack of effect on myogenic contractions), it significantly inhibited spontaneous contractions of the ileum and the uterus. However, the effect of compound 22 was more demonstrated in ACh-induced contractions of the bladder versus ileum and uterus. The detrusor was not responsive to the effects of compound 22 in electric field stimulation- (EFS-) induced contractions. Conversely, the relaxative effect of compound 22 in EFS-induced ileal contraction was comparable to that induced by $\mathrm{ACh}$. In bladder and ileum strips, however, compound 22 was not as potent as atropine, an antimuscarinic drug, in inhibiting ACh-induced contractions $[26,43]$. In the uterus, although compound 22 relaxed oxytocin, prostaglandin F2 $\alpha$, and ACh-induced contractions, its effects were not as potent as those of standard tocolytics (note, however, the similarity in the degree of potency between diclofenac and compound 22 in inhibiting PGF2 $\alpha$-induced contractions) [44]. Nevertheless, the effects of compound 22 were all consistent with the activation of $\mathrm{BK}_{\mathrm{Ca}}$ channels, as evidenced by the counter effects of $\mathrm{BK}_{\mathrm{Ca}}$ channel blockers iberiotoxin or penitrem $\mathrm{A}$ $[26,43,44]$ on the relaxative effects of compound 22 in high $\mathrm{K}^{+}$- $(20 \mathrm{mM} \mathrm{KCl}-)$ induced contractions (Table 1). Other ion channels or contractile machineries may also be at play considering the effects of compound 22 in high- $\mathrm{K}^{+}-(60-$ 80 mM KCl-) induced contractions [26, 43, 44, 48, 49]. Taken together, these findings indicate that in addition to bladderrelaxant activities, compound 22 also influences intestinal and uterine contractions.

\section{Concluding Remarks}

Although $\mathrm{K}^{+}$channel openers hold promise as effective and safer alternatives to many smooth muscle relaxants that are used today, most $\mathrm{K}^{+}$channel openers in development have not lived up to our expectation [14]. A majority of $\mathrm{K}_{\mathrm{ATP}}$ channel openers lacked selectivity and brought unwanted side effects (e.g., cardiovascular) considered worse than those wrought by standard antispasmodics or tocolytics. Thus, the development of $\mathrm{K}_{\mathrm{ATP}}$ channel openers has been discontinued, and the interest was shifted to developing other $\mathrm{K}^{+}$channel openers that are as efficacious as standard smooth muscle relaxants, but with significantly better side effect profile. Recent years have seen great advances in our understanding of the structure and function of existing $\mathrm{K}^{+}$ channels. Due to unmet expectations with $\mathrm{K}_{A T P}$ channel openers, newer channels or associated channel proteins have been characterized as potential drug targets. As stated above, among those explored were the $\mathrm{BK}_{\mathrm{Ca}}$ channels. While the role of $\mathrm{BK}_{\mathrm{Ca}}$ channels in the CNS is complex and still an area of active academic research, there appears to be a consensus on the contribution of these channels to the regulation of smooth muscle tone [41]. In this paper, we reviewed the contribution of benzofuroindole derivatives in the field that searches for ideal compounds for OAB (or for other pathophysiologic conditions). We have stated the remarkable profiles of these compounds if considered as future $\mathrm{OAB}$ drug treatment. Some investigators, however, showed the potency of a certain benzofuroindole analogue (compound 22) to relax ileum and uterine contractions, indicating that like other $\mathrm{K}^{+}$channel openers, selectivity is still an area of concern with benzofuroindole compounds. However, it is still too early to conclude that benzofuroindole analogues have no place in the roll of alternative or safer smooth muscle relaxants. More investigations are required to better understand their mechanics and characteristics and ultimately to address their lack of selectivity. The potency of various benzofuroindole compounds in smooth muscle types can be compared [48] and from there we may discover the drugs' most appropriate clinical application.

Finally, the worth of $\mathrm{BK}_{\mathrm{Ca}}$ channel openers as "better" smooth muscle relaxants is just proven theoretically but not in clinical practice. Not much is known about the physiology of $\mathrm{BK}_{\mathrm{Ca}}$ channels and their activators in the disease state, thus, whether or not a $\mathrm{BK}_{\mathrm{Ca}}$ channel opener will be found to have therapeutic utility will depend on the appropriate counterbalance of $\mathrm{BK}_{\mathrm{Ca}}$ channel activation versus other excitatory inputs [14]. Moreover, some reported $\mathrm{BK}_{\mathrm{Ca}}$ channel openers do not satisfy some of the criteria set in clinical tests to prove their worth as effective smooth muscle relaxants (for review see [41]). This explains, in part, the slow pace in the development of $\mathrm{BK}_{\mathrm{Ca}}$ channel openers as smooth muscle hyperactivity interventions. However, as molecular biology and drug development techniques are getting more and more advanced, it is plausible that, in the next few years, concerns that limit the potential use of $\mathrm{BK}_{\mathrm{Ca}}$ channel openers (especially those that are recently characterized) will be resolved. Therefore, the road ahead may be tedious for 
benzofuroindole compounds, but there is still optimism with regard to their potential use as effective smooth muscle relaxants.

\section{Conflict of Interests}

The authors declare no conflicts of interest.

\section{Acknowledgment}

This work was supported by funds from Sahmyook University.

\section{References}

[1] J. J. Morrison and J. M. Rennie, "Clinical, scientific and ethical aspects of fetal and neonatal care at extremely preterm periods of gestation," British Journal of Obstetrics and Gynaecology, vol. 104, no. 12, pp. 1341-1350, 1997.

[2] H. Karaki, H. Ozaki, M. Hori et al., "Calcium movements, distribution, and functions in smooth muscle," Pharmacological Reviews, vol. 49, no. 2, pp. 157-230, 1997.

[3] A. Vander, J. Sherman, and D. Laciano, Human Physiology: The Mechanism of Body Function, McGraw-Hill, Boston, Mass, USA, 8th edition, 2001.

[4] A. J. Pappano, "Cholinoceptor-activating and cholinesteraseinhibiting drugs," in Basic and Clinical Pharmacology, B. G. Katzung, Ed., pp. 93-107, McGraw-Hill, Singapore, 2007.

[5] T. Godfraind, R. Miller, and M. Wibo, "Calcium antagonism and calcium entry blockade," Pharmacological Reviews, vol. 38, no. 4, pp. 321-416, 1986.

[6] T. Uchiyama and R. Chess-Williams, "Muscarinic receptor subtypes of the bladder and gastrointestinal tract," Journal of Smooth Muscle Research, vol. 40, no. 6, pp. 237-247, 2004.

[7] E. P. Frazier, S. L. Peters, A. S. Braverman, M. R. Ruggieri, and M. C. Michel, "Signal transduction underlying the control of urinary bladder smooth muscle tone by muscarinic receptors and $\beta$-adrenoreceptors," Naunyn-Schmiedeberg's Archives of Pharmacology, vol. 377, pp. 449-462, 2007.

[8] H. H. Zingg and S. A. Laporte, “The oxytocin receptor," Trends in Endocrinology and Metabolism, vol. 14, no. 5, pp. 222-227, 2003.

[9] L. Myatt and S. J. Lye, "Expression, localization and function of prostaglandin receptors in myometrium," Prostaglandins Leukotrienes and Essential Fatty Acids, vol. 70, no. 2, pp. 137148, 2004.

[10] A. Shmygol, J. Gullam, A. Blanks, and S. Thornton, "Multiple mechanisms involved in oxytocin-induced modulation of myometrial contractility," Acta Pharmacologica Sinica, vol. 27, no. 7, pp. 827-832, 2006.

[11] A. Carl, H. K. Lee, and K. M. Sanders, "Regulation of ion channels in smooth muscles by calcium," American Journal of Physiology, vol. 271, no. 1, pp. C9-C34, 1996.

[12] P. R. Conlin and G. H. Williams, "Use of calcium channel blockers in hypertension," Advances in Internal Medicine, vol. 43, pp. 533-562, 1998.

[13] B. Cantabrana, J. R. Perez Vallina, L. Menéndez, and A. Hidalgo, "Spasmolytic and calmodulin inhibitory effect of non-steroidal anti-inflammatory drugs in vitro," Life Sciences, vol. 57, no. 14, pp. 1333-1341, 1995.
[14] T. M. Argentieri and J. A. Butera, "An overview of potassium channel activators for the treatment of overactive bladder: a survey of new structures 2000-2005," Expert Opinion on Therapeutic Patents, vol. 16, no. 5, pp. 573-585, 2006.

[15] K. Gyetvai, M. E. Hannah, E. D. Hodnett, and A. Ohlsson, "Tocolytics for preterm labor: a systematic review," Obstetrics and Gynecology, vol. 94, no. 5, pp. 869-877, 1999.

[16] N. D. Berkman, J. M. Thorp Jr., K. N. Lohr et al., "Tocolytic, treatment for the management of preterm labor: a review of the evidence," American Journal of Obstetrics and Gynecology, vol. 188, no. 6, pp. 1648-1659, 2003.

[17] J. H. Sheldon, N. W. Norton, and T. M. Argentieri, "Inhibition of guinea pig detrusor contraction by NS-1619 is associated with activation of $\mathrm{BK}_{\mathrm{Ca}}$ and inhibition of calcium currents," Journal of Pharmacology and Experimental Therapeutics, vol. 283, no. 3, pp. 1193-1200, 1997.

[18] C. D. Foster, M. J. Speakman, K. Fujii, and A. F. Brading, "The effects of cromakalim on the detrusor muscle of human and pig urinary bladder," British Journal of Urology, vol. 63, no. 3, pp. 284-294, 1989.

[19] G. Edwards, M. Henshaw, M. Miller, and A. H. Weston, "Comparison of the effects of several potassium-channel openers on rat bladder and rat portal vein in vitro," British Journal of Pharmacology, vol. 102, no. 3, pp. 679-686, 1991.

[20] R. Chess-Williams, S. W. Martin, C. Korstanje, and C. R. Chapple, "In vitro investigation of the bladder-vascular selectivity of levcromakalim and YM934 in human tissues," British Journal of Urology International, vol. 83, no. 9, pp. 1050-1054, 1999.

[21] M. E. Brune, T. A. Fey, J. D. Brioni et al., “(-)-(9S)-9-(3bromo-4-fluorophenyl)-2,3,5,6,7,9-hexahydrothieno[3,2-b] quinolin-8(4H)-one 1-dioxide (A-278637): a novel ATPsensitive potassium channel opener efficacious in suppressing urinary bladder contractions. II. In vivo characterization," Journal of Pharmacology and Experimental Therapeutics, vol. 303, no. 1, pp. 387-394, 2002.

[22] A. C. Fabiyi, M. Gopalakrishnan, J. J. Lynch, J. D. Brioni, M. J. Coghlan, and M. E. Brune, "In vivo evaluation of the potency and bladder-vascular selectivity of the ATP-sensitive potassium channel openers (-)-cromakalim, ZD6169 and WAY-133537 in rats," British Journal of Urology International, vol. 91, no. 3, pp. 284-290, 2003.

[23] K. Komersova, J. W. Rogerson, E. L. Conway et al., "The effect of levcromakalim (BRL 38227) on bladder function in patients with high spinal cord lesions," British Journal of Clinical Pharmacology, vol. 39, no. 2, pp. 207-209, 1995.

[24] J. A. Butera, S. A. Antane, B. Hirth et al., "Synthesis and potassium channel opening activity of substituted $10 \mathrm{H}$-benzo[4, 5] furo[3,2-b] indole- and 50-dihydro-indeno[1,2-b]indole-1carboxylic acids," Bioorganic and Medicinal Chemistry Letters, vol. 11, no. 16, pp. 2093-2097, 2001.

[25] A. E. Gormemis, T. S. Ha, I. Im et al., "Benzofuroindole analogues as potent $\mathrm{BK}_{\mathrm{Ca}}$ channel openers," ChemBioChem, vol. 6, no. 10, pp. 1745-1748, 2005.

[26] I. C. Dela Peña, S. Y. Yoon, S. M. Kim et al., "Bladder-relaxant properties of the novel benzofuroindole analogue LDD175," Pharmacology, vol. 83, no. 6, pp. 367-378, 2009.

[27] M. L. Garcia, D. M. Shen, and G. J. Kaczorowski, "Highconductance calcium-activated potassium channels: validated targets for smooth muscle relaxants?" Expert Opinion on Therapeutic Patents, vol. 17, no. 7, pp. 831-842, 2007. 
[28] S. H. Tal, H. H. Lim, E. L. Ga, Y. C. Kim, and C. S. Park, "Electrophysiological characterization of benzofuroindoleinduced potentiation of large-conductance $\mathrm{Ca}^{2+}$-activated $\mathrm{K}^{+}$ channels," Molecular Pharmacology, vol. 69, no. 3, pp. 10071014, 2006.

[29] G. J. Kaczorowski, H. G. Knaus, R. J. Leonard, O. B. McManus, and M. L. Garcia, "High-conductance calciumactivated potassium channels: structure, pharmacology, and function," Journal of Bioenergetics and Biomembranes, vol. 28, no. 3, pp. 255-267, 1996.

[30] S. Ghatta, D. Nimmagadda, X. Xu, and S. T. O’Rourke, "Large-conductance, calcium-activated potassium channels: structural and functional implications," Pharmacology and Therapeutics, vol. 110, no. 1, pp. 103-116, 2006.

[31] M. A. Valverde, P. Rojas, J. Amigo et al., "Acute activation of Maxi-K channels (hSlo) by estradiol binding to the $\beta$ subunit," Science, vol. 285, no. 5435, pp. 1929-1931, 1999.

[32] M. Wallner, P. Meera, and L. Toro, "Molecular basis of fast inactivation in voltage and $\mathrm{Ca}^{2+}$-activated $\mathrm{K}^{+}$channels: a transmembrane $\beta$-subunit homolog," Proceedings of the National Academy of Sciences of the United States of America, vol. 96, no. 7, pp. 4137-4142, 1999.

[33] X. M. Xia, J. P. Ding, and C. J. Lingle, "Molecular basis for the inactivation of $\mathrm{Ca}^{2+}$ - and voltage-dependent BK channels in adrenal chromaffin cells and rat insulinoma tumor cells," Journal of Neuroscience, vol. 19, no. 13, pp. 5255-5264, 1999.

[34] X. Qian, C. M. Nimigean, X. Niu, B. L. Moss, and K. L. Magleby, "Slo1 tail domains, but not the $\mathrm{Ca}^{2+}$ bowl, are required for the $\beta 1$ subunit to increase the apparent $\mathrm{Ca}^{2+}$ sensitivity of BK channels," Journal of General Physiology, vol. 120, no. 6, pp. 829-843, 2002.

[35] C. Vergara, R. Latorre, N. V. Marrion, and J. P. Adelman, "Calcium-activated potassium channels," Current Opinion in Neurobiology, vol. 8, no. 3, pp. 321-329, 1998.

[36] M. J. Coghlan, W. A. Carroll, and M. Gopalakrishnan, "Recent developments in the biology and medicinal chemistry of potassium channel modulators: update from a decade of progress," Journal of Medicinal Chemistry, vol. 44, no. 11, pp. 1627-1653, 2001.

[37] G. M. Dick, A. C. Hunter, and K. M. Sanders, "Ethylbromide tamoxifen, a membrane-impermeant antiestrogen, activates smooth muscle calcium-activated large-conductance potassium channels from the extracellular side," Molecular Pharmacology, vol. 61, no. 5, pp. 1105-1113, 2002.

[38] Y. Imaizumi, K. Sakamoto, A. Yamada et al., "Molecular basis of pimarane compounds as novel activators of largeconductance $\mathrm{Ca}^{2+}$-activated $\mathrm{K}^{+}$channel $\alpha$-subunit," Molecular Pharmacology, vol. 62, no. 4, pp. 836-846, 2002.

[39] K. M. Giangiacomo, A. Kamassah, G. Harris, and O. B. Mcmanus, "Mechanism of maxi-K channel activation by dehydrosoyasaponin-I," Journal of General Physiology, vol. 112, no. 4, pp. 485-501, 1998.

[40] G. J. Kaczorowski and M. L. Garcia, "Pharmacology of voltagegated and calcium-activated potassium channels," Current Opinion in Chemical Biology, vol. 3, no. 4, pp. 448-458, 1999.

[41] A. Nardi and S. P. Olesen, "BK $\mathrm{Ca}$ channel modulators: a comprehensive overview," Current Medicinal Chemistry, vol. 15, no. 11, pp. 1126-1146, 2008.

[42] G. McMurray, J. H. Casey, and A. M. Naylor, "Animal models in urological disease and sexual dysfunction," British Journal of Pharmacology, vol. 147, no. 2, pp. S62-S79, 2006.
[43] I. C. Dela Peña, S. Y. Yoon, S. M. Kim et al., "Inhibition of intestinal motility by the putative $\mathrm{BK}_{\mathrm{Ca}}$ channel opener LDD175," Archives of Pharmacal Research, vol. 32, no. 3, pp. 413-420, 2009.

[44] H. S. Ahn, I. dela Peña, J. H. Ryu, Y. C. Kim, and J. H. Cheong, "4-chloro-7-trifluoromethyl-10H-benzo[4,5]furo[3,2-

$b$ ] indole-1-carboxylic acid (TBIC), a putative $\mathrm{BK}_{\mathrm{Ca}}$ channel opener with uterine-relaxant activities," Pharmacology, vol. 1, no. 87(5-6), pp. 331-340, 2011.

[45] R. N. Khan, B. Matharoo-Ball, S. Arulkumaran, and M. L. J. Ashford, "Potassium channels in the human myometrium," Experimental Physiology, vol. 86, no. 2, pp. 255-264, 2001.

[46] B. Chanrachakul, B. Matharoo-Ball, A. Turner et al., "Immunolocalization and protein expression of the $\alpha$ subunit of the large-conductance calcium-activated potassium channel in human myometrium," Reproduction, vol. 126, no. 1, pp. 43-48, 2003.

[47] R. Schubert and M. T. Nelson, "Protein kinases: tuners of the $\mathrm{BK}_{\mathrm{Ca}}$ channel in smooth muscle," Trends in Pharmacological Sciences, vol. 22, no. 10, pp. 505-512, 2001.

[48] J. Malysz, S. A. Buckner, A. V. Daza, I. Milicic, A. PerezMedrano, and M. Gopalakrishnan, "Functional characterization of large conductance calcium-activated $\mathrm{K}^{+}$channel openers in bladder and vascular smooth muscle," NaunynSchmiedeberg's Archives of Pharmacology, vol. 369, no. 5, pp. 481-489, 2004.

[49] H. Kobayashi, S. Adachi-Akahane, and T. Nagao, "Involvement of $\mathrm{BK}_{\mathrm{Ca}}$ channels in the relaxation of detrusor muscle via $\beta$-adrenoceptors," European Journal of Pharmacology, vol. 404, no. 1-2, pp. 231-238, 2000. 

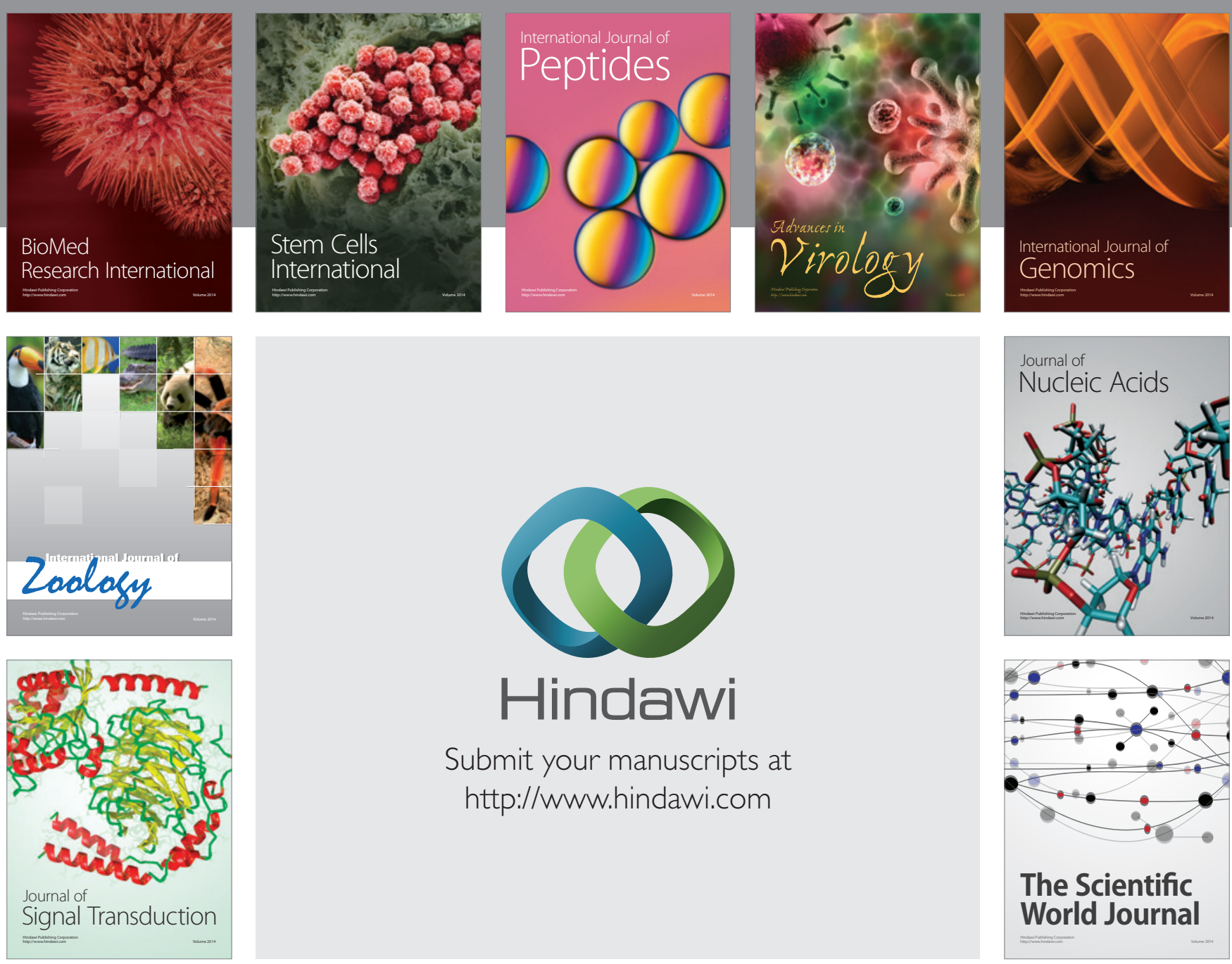

Submit your manuscripts at

http://www.hindawi.com
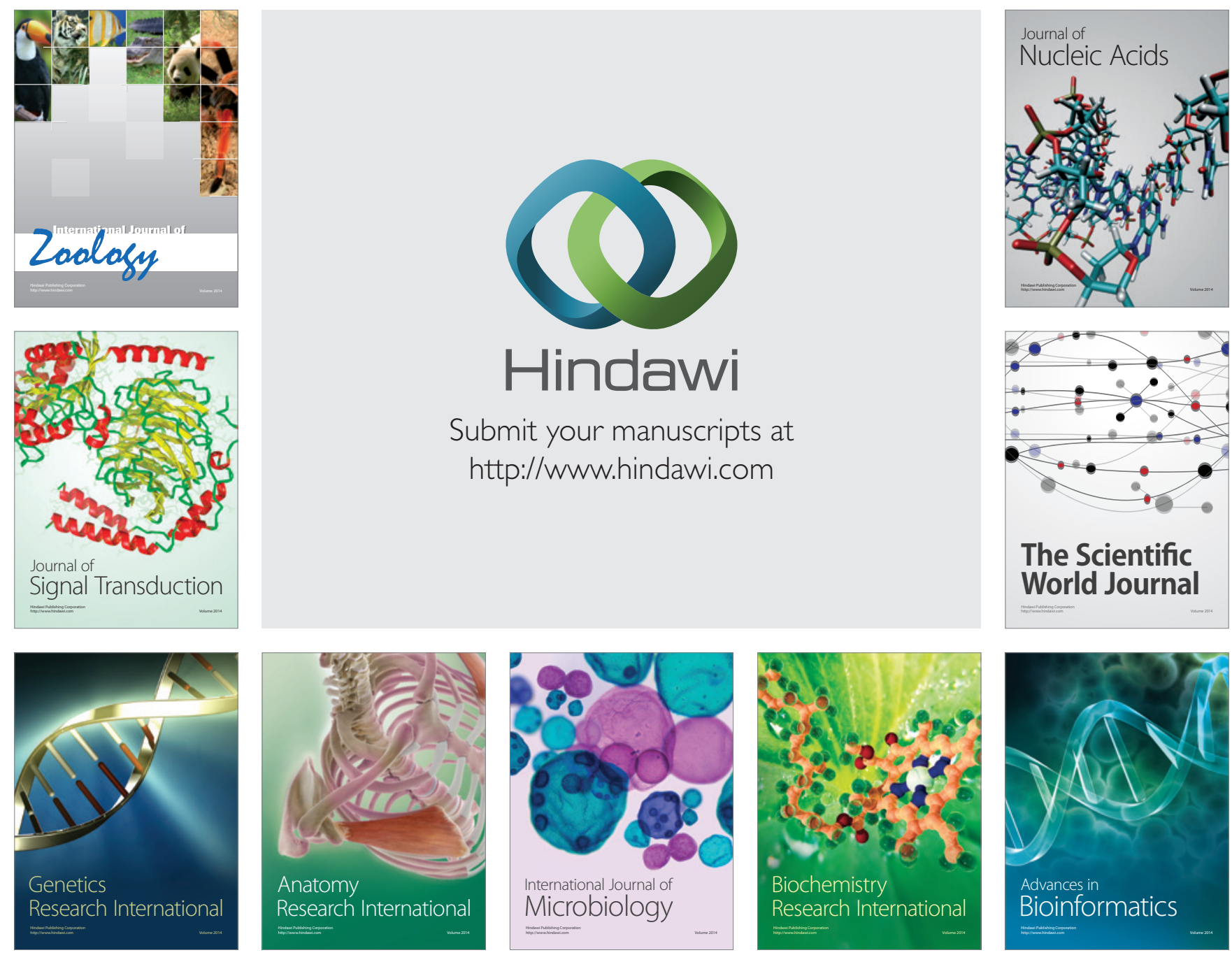

The Scientific World Journal
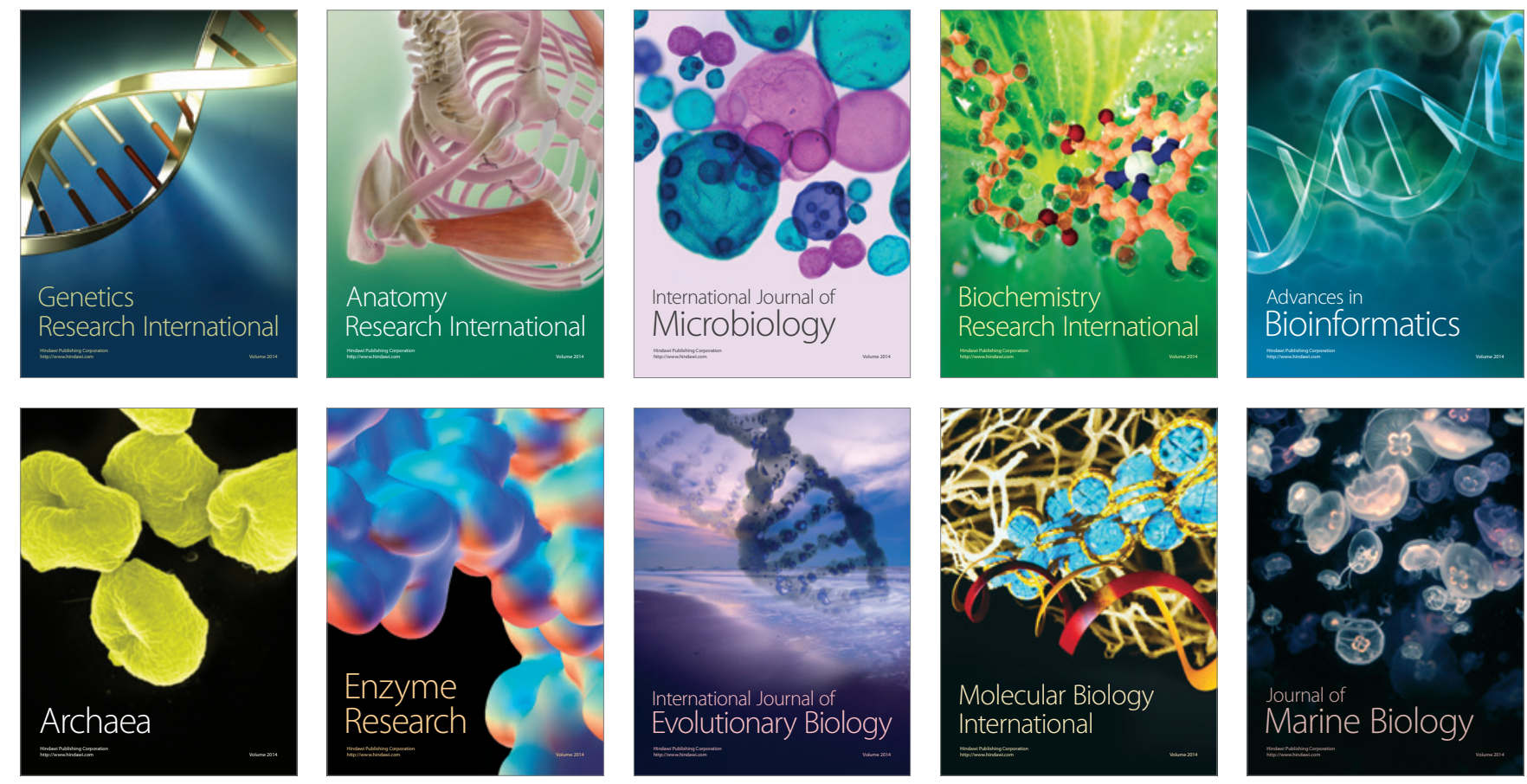